\title{
The Effect of "Bilingualism" on Iranian ELT Student's "Critical thinking ability" (CT)
}

\author{
Pegah Merrikhi \\ University of Khatam, Tehran, Iran \\ Email: Deniz.qizi@gmail.com
}

\begin{abstract}
This paper presents the results of a study of the effect of bilingualism on the critical thinking ability of two groups of Iranian university ELT, M.A students: one composed of Azeri-Turkish bilinguals and the other, of Persian monolinguals. The study attempted to ascertain whether bilinguals would do better than monolinguals on a critical thinking questionnaire and whether males and females would perform differently. Subjects were given the CT questionnaire to answer. The results were then analyzed, and it was concluded that while there was no statistically significant difference between males and females, bilinguals definitely outperformed monolinguals on the $\mathrm{CT}$ questionnaire. Given these results, bilingual education programs beginning in early elementary school were recommended for Iran.
\end{abstract}

Index Terms — critical thinking, bilingualism, gender differences, Turkish, Persian

\section{INTRODUCTION}

It has been observed that bilingualism as both a cognitive and social feature of a person is influenced by the details of the individual's life and also has effects upon language education and related domains ((Raymond et all, 2002).It would then be logical to assume that there must be some relationship between bilingualism and a cognitive or mental ability such as critical thinking. This article attempts to answer the question: does bilingualism affect critical thinking (CT)? In addition, since gender differences have been observed in many areas of linguistic and cognitive performance, the study aims to determine if there are any differences due to gender in CT.

Critical Thinking is the process of using reasoning to discern what is true and what is false in the utterances we hear and the texts we read every day. CT involves being familiar with logic and logical fallacies, those bits of false reasoning that are used to manipulate and mislead us, as well as being able to separate facts from opinions. CT also entails being fair and open minded, not dismissing anything without examination, and not accepting anything without examination. It further involves asking questions of yourself and others, because that is how we uncover the truth and the motivations behind the arguments, along with self-regulation, the ongoing process of making sure that you have not fallen into any of the logical fallacies or rationalizations yourself.

Ideal critical thinkers are open minded; ready and eager to explore all ideas and all points of view, including those alien or opposed to their own.

They are not threatened by opposing views, because they are looking for the truth; they know that if they have it already, it will stand any scrutiny. And if they don't have it, they are willing to drop the falsehoods they have, and embrace it.

Critical thinkers question everything; using their tools to ferret out the truth, wherever it may hide. The tools they use are Logic, Research, and Experience.

Critical thinking can not only make you manipulation proof, it can open new vistas for you, as things previously hidden become clear. Meyers (1986)

Critical thinking has been called one of the most important attributes for success in the $21^{\text {st }}$ century (Hui_, 1998). Meyers (1986) argued that for students to reach their fullest potential in today's society, they must learn to think and reason critically. Paul (2002) contended that in a world of accelerating change, intensifying complexity and increasing interdependence, critical thinking is now a requirement for economic and social survival.

Minority students in Iran among them the Turkish, Armenians, Azeris, Kurds, ARABS, Baluchis, Turkmen, Assyrians, and Georgians) come to school speaking their own native languages and have to study in Farsi while most of the times they do not have enough command on Farsi as language of instruction and on the other hand they become compound bilinguals as the result of being exposed to Farsi before their critical period. After that in guidance school they learn English as their third language, but many students nowadays in modern Iran start learning English before guidance schools in language institutes and gradually English becomes their foreign language. If critical thinking is required for survival in modern Iran, then the question arises as to whether minority groups in Iran as bilinguals are more critical thinkers or not? 


\section{A. Critical Thinking Defined}

Critical thinking, a common term in educational, psychological, and philosophical circles, has been defined by researchers and theorists as a "set of intellectual standards" that can be used by individuals while thinking (Paul, 1995). Chafee (1988) defined critical thinking as "our active, purposeful, and organized efforts to make sense of our world by carefully examining our thinking, and the thinking of others, in order to clarify and improve our understanding" (p. 29)

Though it is difficult to find a universally accepted definition of critical thinking, there appears to be similar themes as noted in scholarly publications. Some even consider critical thinking as an essential skill, which is required to function in society (Celuch and Slama, 1999). Conceptually, this could show a difference in critical thinking skills among various age groups and those with greater life experiences.

Critical thinking definitions range from the simple to the complex. Robert Ennis (1991) simply defined critical thinking as "reasonable and reflective thinking focused on deciding what to do or believe." Paul (1995) wrote that the "master of critical thinking" uses a set of intellectual standards while thinking. These standards guide the thinking process as well as help individuals heighten their ability to think critically. "The ideal critical thinker is habitually inquisitive, well-informed, trustful of reason, open-minded, flexible, fair-minded in evaluation, honest in facing personal biases, prudent in making judgments, willing to reconsider, clear about issues, orderly in complex matters, diligent in seeking relevant information, reasonable in the selection of criteria, focused in inquiry, and persistent in seeking results which are as precise as the subject and the circumstances of inquiry permit" (Paul,1 995, p. 2). Extending from Facione's work, Rudd, Baker and Hoover (2000) defined critical thinking as: "A reasoned, purposive, and introspective approach to solving problems or addressing questions with incomplete evidence and information and for which an incontrovertible solution is unlikely" (p. 5).

Along the same lines, The Foundation for Critical Thinking (1997) states that:

"...critical thinking is associated with the following elements of reasoning: purpose of the thinking, key issue or question being considered, assumptions, point of view, evidence, concepts, and ideas, inferences or interpretations, and implications or consequences (Celuch and Slama, 1999, p. 2)."

Both of the above definitions require the critical thinker to identify a question and to gather information associated with the question. The critical thinker is then to draw on past knowledge and experience in order to evaluate a possible outcome in resolving the question. Possibly the most important aspect of the process is the ability of the critical thinker to foresee possible outcomes and apply the best solution to the question.

Peter Facione (1996) discusses the challenge and difficulty a group of subject experts had in developing a consensus when defining critical thinking. In doing so, he discusses the impacts, similar to those elements stated in the above definitions; have on the subject in which the critical thinker is undertaking. These, and other elements such as inquisitiveness, open mindedness, analytical, self confidence, sytematicity, cognitive maturity, and truth-seeking can also impact the dimensions of critical thought which have to be broken down into affective and cognitive strategies for critical thinking to take place (Facione, 1996, and Paul, Binker, Jensen, and Kreklau, 1990).

This is further evidenced in the definition provided by the American Philosophical Association. They state:

“...the process of purposeful, self-regulatory judgement. This process gives consideration to evidence, contexts, conceptualizations, methods, and criteria (The APA Delphi Report, 1990 cited in Facione 1998)."

The underlying theme of these definitions and the discussions that accompany them describe the formula for "problem-solving" and a process for "decision-making." The five steps in the problem solving formula are, identifying the problem, gather data, consider possible solutions, apply the best solution, and evaluate the consequences. Therefore, explaining the value and importance of critical thinking by managers (Guffey, 1996). After all, is this not the role of a manager? If it were not for the need to solve problems and make decisions, there would be no need for managers.

Similarly, hospitality managers are asked to draw on their education, life experience, and practical experience in the performance of their job. Moreover, many hospitality companies recruiting hospitality graduates require the prospective manager to have had some kind of field experience to draw from. Likewise, all, if not most, hospitality programs have made some kind industry simulation laboratory experience part of their curriculum. Each of these experiences establishes some base for the student to draw from when they are solving problems and thinking critically in the professional role of a hospitality manager. Demanding these educational experiences for students, academic institutions and hospitality management programs in particular, recognize the need for critical thinking skills in management.

\section{B. The Need for Critical Thinking}

A common complaint among educators is the generalization that students of today are lazy and lack the desire to investigate answers to questions. Instead, they would rather that the educators give them the answers and let them regurgitate that answer back to them on an exam. Not soon enough, the students realize that they will be paid to resolve problems and come up with the answer on their own with a more severe penalty than losing a few points on an exam (Bowmen, 1987).

However, corporate structure and leadership styles of many industries, the hospitality industry included, do not always foster or encourage critical thinking skills by lower level managers and employees. The autocratic leadership style of the boss making all the decisions does not promote problem solving or critical thinking by lower level workers. Furthermore, some industries, such as quick service restaurants, and other foodservice operations, have become so 
procedure oriented that they do not allow for creative problem solving or critical thinking by workers. Instead, managers are asked to refer to the procedure manual to solve the problem at hand.

This is but one criticism of the "promotion from within" practice, taking place in many retail and restaurant operations. The concept that a senior hourly employee, who knows all the procedures, practices, and tasks to be completed in a business, will make a good leader and/or manager does not consider the critical thinking skills necessary for the position. This is further evidenced in a study by Kepner-Tregoe where business managers and employees said their companies limited the thinking necessary in problem-solving and decision making. In the study, nearly half of both managers and employees said it was difficult to obtain the information needed to solve problems, make decisions, and draw up plans. The development and utilization of critical thinking skills by the entire workforce is imperative for future success (Allnoch, 1997).

Other research suggests that employers are looking for critical thinking skills when recruiting new college graduates. According to a study by Mathew Mariani, those qualities rated as "almost always important as a job performance indicator" include sincerity, eagerness, decision-making skills, critical thinking, initiative, professional attitude, and oral communication and verbal skills (Mariani, 1994).

\section{Bilingualism}

Becoming bilingual is a way of life. Your whole person is affected as you struggle to reach beyond the confines of your first language and into a new language, a new culture, a new way of thinking, feeling, and acting (Brown 1994 p. 1).

The 'wholistic' view of bilingualism (Grosjean, 1992) provides an explanation of the different cognitive abilities of monolingual and bilingual individuals by taking their differential use of language into account. The approach states that 'the bilingual... has a unique and specific linguistic configuration' (Grosjean, 1992, p. 55) and proposes that by using two languages in interacting ways, the bilingual individual develops a distinct linguistic system not to be found in monolingual comparisons. According to this, the differing outcomes of the two language groups observed in tasks assessing cognitive functioning are thought to be caused by the difference in the bilingual's underlying composition of language.

As further argued by Bialystok (1999) the bilingual realises the arbitrariness of language and understands that one word may come to represent many things. In this way, the interpretation and association of words for the bilingual, requires an advanced representation because more abstract connections are made between them.

Indeed, it is apparent from many studies of the cognitive abilities of children that there is an advantage to be gained from the early acquisition of a second language.

Developmental differences in many aspects of cognitive control have been identified between bilingual and monolingual children, particularly in the completion of tasks which require a large amount of attention and selection. Bilingual children also demonstrate greater efficiency when switching from one task to another, showing evidence of many uniquely advanced skills in what is known as 'executive functioning' (Bialystok, 2005). To summarize the term, executive functioning involves an "awareness to operate intentionally and an inhibition mechanism to suppress the more automatic responses of the lower levels" (Bialystok, 1999, p. 637).

According to Baker (1993) bilingualism is not simply the ability to speak two languages but also must include the components of written expression. Most recent research into bilingualism focuses on oracy and literacy-the four basic abilities of listening, speaking, reading, and writing.

Cummins (2000) develops the concept of a cognitive competency, the ability to reason and think, as a fifth ability factor in bilingualism. This notion was first introduced by (Skutnabb-Kangas 1981, cited in website) who referred to the ability to use both languages as thinking tools. Cummins (2000) took it farther and included the ability to reason and create new cognitive patterns or neural networks capable of handling the abstract uses of language that make up the deep structure of communication. According to him, Bilingualism and multilingualism must include the ability to continue growth in low frequency, abstract vocabulary and linguistically complex structures.

According to (Linda Orr Easthouse, 2003), if we agree that bilingualism is the ability to read, write, speak, listen, and think in two languages, then we can see that most learners will not be able to gain all five competencies

- Pronunciation (phonetic aptitudes),

-vocabulary (lexical development),

-grammar (syntax and rule development),

-meaning (comprehension and discourse features), and style (context, register, function) in both languages within in a shortened time frame, especially given the kinds of programs offered.

But (Baker 2006) thinks; since a bilingual uses two languages for different purposes, in different domains of life and with different people, equal competence in both languages is a myth. It should be noted that language proficiency in both monolinguals and bilinguals consists of a diverse combination of skills (i.e., speaking, writing, listening and reading) that are not necessarily correlated. An individual's proficiency may vary across the different skills. While some bilinguals show very high levels of proficiency in both languages in the written and oral abilities, others' comprehension or speaking skills are related to the specific domains of experiences with using two languages. Therefore, proficiency needs to be assessed in a variety of areas. 
Bloomfield (Romaine1995: 11) describes bilingualism as native-like control of two languages. This means that you have to presume the idea of a perfect bilingual person. According to Bloomfield, there should not exist any kind of shortcomings in the second language. In order to be considered as bilingual according to Bloomfield's definition, a speaker has to have an extensive vocabulary as well as perfect skills in reading, writing, listening and speaking. Assuming native control of two languages as a prerequisite for bilingualism means that there would be less people considering themselves to be bilingual.

Often people have knowledge gaps in their mother tongue since both a language and the individual develop over time. To be up-to-date with two languages is arguably impossible. Other linguists are less strict in their definitions of bilingualism.

Titone defines bilingualism as "the individual's capacity to speak a second language while following the concepts and structures of that language rather than paraphrasing his or her mother tongue" (Easthouse 2003). Titone maintains that people who have the ability to hold a conversation in a different language are bilingual. His definition includes people that manage to communicate in a second language without being perfectly proficient. This means that in order to consider someone as bilingual that person does not need to have perfect skills in reading and writing, for example, as long as he/she has the capacity to communicate in the language's different communicative modes. Other definitions are more open to interpretation.

Haugen states in his definition that "Bilingualism begins when the speaker can produce complete, meaningful sentences in another language” (Karosas: 2004).

Haugen does not imply native control and states that someone is already bilingual when he/she can make useful and meaningful utterances in another language. That means that almost anyone that acquires another language can be seen as bilingual, even though he/she would never consider him/herself as bilingual. Haugen's definition is questionable because people who manage to make meaningful utterances might still not be able to have fluent conversations in their second language. Furthermore, the definition does not take into account other skills such as listening or writing. An even looser definition of bilingualism is presented by Diebold.

Diebold sees anyone who knows a few words in another language as bilingual.

Diebold's term is incipient bilingualism. Incipient bilingualism means "the initial stages of contact between two languages (Leinyui:2006) Diebold's view on bilingualism is in other words very broad and open. For example, Diebold would consider a person who merely knows a few single content words without even being to able to link them together as bilingual. Diebold's definition has no clear criteria and leaves too many question marks to be of any practical use.

Similarly, Edwards considers anyone who speaks a few words of another language as bilingual. The degree of bilingualism develops as the individual's language competence improves.

\section{METHODOLOGY}

\section{A. Subjects}

A total of 120 ELT M.A students in both monolingual and bilingual groups were chosen for this study. Each group consisted of 30 male and 30 female students. The range of age was between 23-33 and they belong approximately to the same social class. The students were asked to volunteer by their prospective instructor and given the exam instrument. All individuals were guaranteed confidentiality. The only information asked of the individual subjects was social class, gender, and age. Subjects were then asked to read a statement of critical thinking questionnaire (see appendix A). There was no time limit placed on the participants to complete the entire appraisal exercise. But it usually took less than 30 minutes to complete.

\section{B. Instrumentation}

For the purpose of measuring the subjects' CT ability, a critical thinking disposition and skills instruction manual By Irani. T, Rudd. R, Gallo. M, Ricketts. J, Freidel. C, \& Rhoades.E (2007) (the manual can be found in Appendix A) was used to measure their $\mathrm{CT}$.

\section{Data Collection Method}

The data used in this study represent the answers of 60 Persian and 60 Azeri Turkish, M.A students in ELT classes. The subjects were asked to volunteer for the study and then given the thirty- questions. The answer sheets were collected and given to the researcher. All the answer sheets were collected within a month in both bilingual and monolingual areas. And then answer sheets were returned to the researcher for final analysis.

\section{Data Analysis and Discussion}

After distributing the CT questionnaire (Appendix) among ELT students to each group, the questionnaires were collected about after half an hour, there were no pressure of time and the students had enough time to answer them. Then the researcher scored their answers out of the total mark 150. She calculated the average performance of each group once as a whole (both males and females within each group), and obtained the average Performance of each group as a whole to compare the performance of bilinguals to monolinguals (Table 3) then she compared the same 
genders of each group; i.e monolingual females with bilingual females (Table 1) and monolingual males with bilingual males (Table 2) and then she argued the scores in this three way.

TABLE 1

AVERAGE PERFORMANCE OF FEMALES IN EACH GROUP

\begin{tabular}{|c|c|c|c|}
\hline Monolingual female scores & Frequency & Bilingual Female scores & Frequency \\
\hline 60 & 4 & 82 & 2 \\
\hline 70 & 2 & 86 & 2 \\
\hline 74 & 2 & 90 & 2 \\
\hline 82 & 2 & 95 & 2 \\
\hline 84 & 2 & 98 & 2 \\
\hline 85 & 4 & 99 & 4 \\
\hline 90 & 2 & 100 & 4 \\
\hline 95 & 2 & 102 & 2 \\
\hline 100 & 4 & 108 & 2 \\
\hline 105 & 4 & 109 & 2 \\
\hline 110 & 2 & 134 & 2 \\
\hline$€ X f=2408$ & 2 & 135 & 2 \\
\hline$€ X / N=2408 / 30$ & 2 & 150 & 2 \\
\hline$€ X / \mathrm{N}=80.2$ & $\mathrm{~N}=30$ & $\begin{array}{l}€ X f=3074 \\
€ X / N=3074 / 30 \\
€ X / N=102.4\end{array}$ & $\mathrm{~N}=30$ \\
\hline
\end{tabular}

$\mathrm{Mono} / \mathrm{F}=€ \mathrm{X} / \mathrm{N}=93.99$

$\mathrm{Bi} / \mathrm{F}=€ X / \mathrm{N}=106.46$

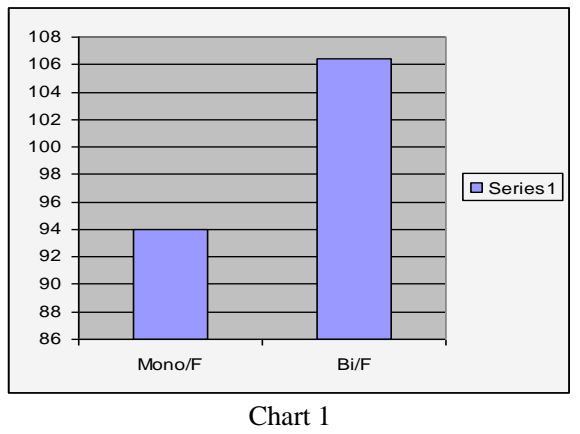

TABLE 2

AVERAGE PERFORMANCE OF MALES IN EACH GROUP

\begin{tabular}{|l|l|l|l|}
\hline \multicolumn{4}{|c|}{ AVERAGE PERFORMANCE OF MALES IN EACH GROUP } \\
\hline Monolingual male scores & Frequency & Bilingual male scores & Frequency \\
70 & 4 & 82 & 2 \\
74 & 2 & 86 & 2 \\
82 & 2 & 90 & 2 \\
84 & 2 & 150 & 2 \\
85 & 4 & 98 & 2 \\
90 & 2 & 99 & 4 \\
95 & 2 & 100 & 4 \\
100 & 2 & 145 & 2 \\
105 & 4 & 108 & 2 \\
110 & 2 & 109 & 2 \\
$€ X m=2408$ & 2 & 134 & 2 \\
$€ X / \mathrm{N}=2408 / 30$ & 2 & 135 & 2 \\
$€ X / \mathrm{N}=80.2$ & & 150 & 2 \\
& & $€ X m=3372$ & \\
& & $€ X / \mathrm{N}=3372 / 30$ & \\
& & $€ X / \mathrm{N}=112.4$ & \\
\hline
\end{tabular}

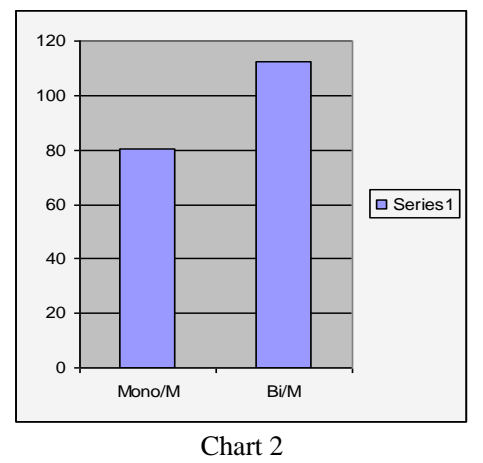


TABLE 3

AVERAGE PERFORMANCE OF EACH GROUP AS WHOLE (F \&M)

\begin{tabular}{|l|l|}
\hline The average of Bilinguals' scores & $€ X \mathrm{Xf}+€ \mathrm{Xm}=€ \mathrm{Xw}$ \\
& $102.4+112.4=214.8$ \\
& $€ \mathrm{Xw} / \mathrm{N}=214.8 / 60=3.58$ \\
\hline The average of monolinguals' scores & $€ X \mathrm{Xm}+€ \mathrm{Xf}=€ \mathrm{Xw}$ \\
& $€ \mathrm{Xw} / \mathrm{N}=80.2+80.2=160.4$ \\
& $€ X \mathrm{Xw} / \mathrm{N}=160.4 / 60=2.67$ \\
\hline
\end{tabular}

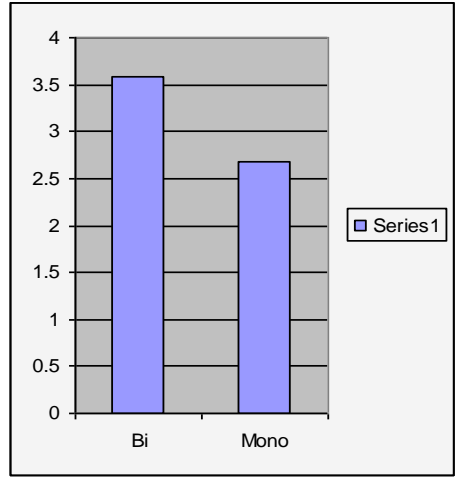

Chart 3

As shown in tables and in charts, bilingual group obtaining the total score of 214.8. In comparison to the mono group's 160.4 score, outperformed in CT manual. However, no clear superiority due to gender was found across the groups. In bilingual group males scored higher than females (112 in comparison to 102) and in monolingual group females and males gained the same score 80 . Comparing subjects of the same gender in each group, it was found that both females and males of the bilingual group did better than the monolingual group. So it can not be concluded that there is any superiority due to gender in CT ability, but it can be demonstrated that Bilingualism apart from all its negative effects influences $\mathrm{CT}$ in a positive way.

\section{CONCLUSION AND IMPLICATION}

Critical thinking is an eminently practical goal and value. It is focused on an ancient Greek ideal of "living an examined life". It is based on the skills, the insights, and the values essential to that end. CT is a way of going about living and learning that empowers us and our students in quite practical ways. When taken seriously, it can transform every dimension of school life: how we formulate and promulgate rules; how we relate to our students; how we encourage them to relate to each other; how we cultivate their reading, writing, speaking, and listening; what we model for them in and outside the classroom.

Of course, we are likely to make critical thinking a basic value in school only insofar as we make it a basic value in our own lives. Therefore, to become adept at teaching so as to foster critical thinking, we must become committed to thinking critically and reflectively about our own lives and the lives of those around us. We must become active, daily, practitioners of critical thought. We must regularly model for our students what it is to reflectively examine, critically assess, and effectively improve the way we live.

So based upon the above mentioned statements, the review of the related literature, and the obtained results, we can conclude that if bilingualism has positive impacts on critical thinking, we should provide the students of Iran with bilingual programs beginning in elementary schools. Providing this opportunity to all Iranian students will improve their chances for a better life and perhaps help to cerate a more equitable society.

\section{APPENDIX}

EMI: Critical Thinking Disposition Assessment

Directions: Indicate how much you agree or disagree with each numbered statement by circling the appropriate number. $1=$ Strongly disagree \& $5=$ Strongly agree.

1. I listen carefully to the opinions of others even when they disagree with me.

2. I look for opportunities to solve problems.

3. I am interested in many issues.

4. I enjoy learning about many topics.

5. I am able to relate to a wide variety of issues.

6. I ask lots of questions in a learning environment.

\begin{tabular}{|c|c|c|c|}
\hline \multicolumn{3}{|c|}{ SD } & SA \\
\hline 1 & 2 & 3 & 4 \\
\hline 1 & 2 & 3 & 4 \\
\hline 1 & 2 & 3 & 4 \\
\hline 1 & 2 & 3 & 4 \\
\hline 1 & 2 & 3 & 4 \\
\hline 1 & 2 & 3 & 4 \\
\hline
\end{tabular}


7. I enjoy fi nding answers to challenging questions.

8. I am a good problem solver.

9. I am confi dent that I can reach a reasonable conclusion.

10. I strive to be well informed.

11. I am likely to change my opinion when I am given new information that conflicts with my current opinion.

12. I enjoy solving problems.

13. I try to consider the facts without le_ing my biases aff ect my decisions.

14. I am able to apply my knowledge to a wide variety of issues.

15. I enjoy learning even when I am not in school.

16. I can get along with people who do not share my opinions.

17. I am able to explain things clearly.

18. I ask good questions when trying to clarify a solution.

19. I present issues in a clear and precise manner.

20. I consider how my own biases affect my opinions.

21. I search for the truth even when it makes me uncomfortable.

22. I keep on working on things until I get them right.

23. I will go out of my way to find the right answers to a problem.

24. I try to find multiple solutions to problems.

25. I ask many questions when making a decision.

26. I believe that most problems have more than one solution.

$\begin{array}{ccccc}1 & 2 & 3 & 4 & 5 \\ 1 & 2 & 3 & 4 & 5 \\ 1 & 2 & 3 & 4 & 5 \\ 1 & 2 & 3 & 4 & 5\end{array}$

27.. I listen carefully to the opinions of others even when they disagree with me.

28. I am likely to change my opinion when I am given new information that conflicts with my current opinion.

29. I try to consider the facts without letting my biases affect my decisions.

30. I can get along with people who do not share my opinions.

$\begin{array}{ccccc}1 & 2 & 3 & 4 & 5 \\ 1 & 2 & 3 & 4 & 5 \\ 1 & 2 & 3 & 4 & 5 \\ 1 & 2 & 3 & 4 & 5 \\ 1 & 2 & 3 & 4 & 5 \\ 1 & 2 & 3 & 4 & 5 \\ 1 & 2 & 3 & 4 & 5 \\ 1 & 2 & 3 & 4 & 5 \\ 1 & 2 & 3 & 4 & 5 \\ 1 & 2 & 3 & 4 & 5 \\ 1 & 2 & 3 & 4 & 5 \\ 1 & 2 & 3 & 4 & 5 \\ 1 & 2 & 3 & 4 & 5 \\ 1 & 2 & 3 & 4 & 5 \\ 1 & 2 & 3 & 4 & 5 \\ 1 & 2 & 3 & 4 & 5 \\ 1 & 2 & 3 & 4 & 5 \\ & & & & \\ 1 & 2 & 3 & 4 & 5 \\ 1 & 2 & 3 & 4 & 5 \\ 1 & 2 & 3 & 4 & 5\end{array}$

CUniversity of Florida, 2007

Suggested citation

Irani, T., Rudd, R., Gallo, M., Ricke_s, J., Friedel, C., \& Rhoades, E. (2007). Critical thinking instrumentation manual. Retreived month day, year, from $\mathrm{h}_{-}$p://step.ufl .edu/resources/critical_thinking/ctmanual.pdf.

300210

\section{ACKNOWLEDGMENT}

I would like to thank all who have made this piece of work possible. I am very grateful to the M.A ELT students of Tabriz university students and Tehran Khatam university students who patiently answered to my CT questionnaire. I would particularly thank Dr Fahim for all his help and encouragement over this paper.

\section{REFERENCES}

[1] Allnoch, Allen.(1997). A Crisis in Critical Thinking. IIE Solutions, 29, (9), 12- 20.

[2] Baker, C. (2006), Foundations of Bilingual Education and Bilingualism. New York, Multilingual Matters.

[3] Bowmen, Ezra.(1987). "Can Colleges Teach thinking?" Time, 61.

[4] Brown, H.D. (1994). Principles of language learning and teaching, New York, Oxford University Press.

[5] Bialystok, E., (1999). Cognitive Complexity and Attention Control in the Bilingual Mind. Child Development, New York: Oxford University Press 3, (636-644).

[6] Bialystok E. (2005). Consequences of bilingualism for cognitive Development, New York: Oxford University Press.

[7] Celuch, Kevin and Slama, Mark. (1999, Jan/Feb). "Teaching Critical Thinking Skills for the 21st Century: an Advertising Principles Case Study.” Journal of Education for Business, 74, (3), 134-150.

[8] Chaffee, John (1992). "Teaching Critical Thinking across the Curriculum." Critical Thinking: New Directions for Community Colleges (77), 25-35.

[9] Crystal, D (1997). Language Death. West Nyack, NY: Cambridge University Press.

[10] Cummins, J. (2000). Language, power, and pedagogy. Bilingual Research Journal, 19, (3), 210-233.

[11] Ennis, R.H. (1991). Critical thinking tests. In A. Costa (Ed.), Developing minds. Washington, DC: Association for Supervision and Curriculum Development. Pp. 368-369.

[12] Facione, Peter A. (2006). "Critical Thinking: What It Is and Why It Counts." California Academic Press.

[13] Facione, Peter A (1998) "Delphi's Report”, California, Academic Press.

[14] Grosjean, F. (1992). Another view of bilingualism. In R. Harris (Ed.), Cognitive processing in bilinguals (p. 51-62). Amsterdam: Elsevier.

[15] Guffey, Mary Ellen. (1996). "Business Communication: Process and Product." 2E, Cincinnati: South-Western College Publishing, (Chapter 1).

[16] Hui_, W. (1998). Critical thinking: An overview. Educational Psychology Interactive. Valdosta, GA: Valdosta State University. Retrieved October 25, 2006, from h_p://chiron.valdosta.edu/whui_/col/cogsys/cri_hnk.html 
[17] Karosas, Susanna. (2004). Bilingualism in Theory and Practice, (www.svenskamammor.com/uppsats.htm)

[18] Keshavarz, M. H. (2000). child language acquisition, infant bilingualism, Phonological development. Iran, Issues in Applied Linguistics, 1-64.

[19] Leinyui, Usmang Salle. (2006). Bilingualism. (http://www.translationdictionary.com/article419.htm)

[20] Meyers. (1986). Critical thinking: impact on nursing. Education Journal of Advanced Nursing, 16(5), $529-533$.

[21] Mariani, Matthew. (1994). "What Employers Want from College Grads." Occupation Outlook Quarterly, 38(2) 42- 1/3.

[22] Orr Easthouse, Linda. (2003). Becoming Bilingual is a way of life (http://www.sil.org/asia/ldc/ arallel_papers/linda_easthouse.pdf)

[23] Paul, R. (1995). Critical thinking: How to prepare students for a rapidly changing world. Santa Rosa, CA: Foundation for Critical Thinking.

[24] Paul, R., \& Elder, L (2002). A miniature guide for those who teach on how to improve student learning: 30 practical ideas. Dillon Beach, CA: Foundation for Critical Thinking.

[25] Raymond, A; Rachel A, Radsma,, J. (2002). Journal of professional nursing, 18 (4) :220-9.

[26] Romaine, Suzanne. (1995). Bilingualism, 2nd edition, Merton College: University Of Oxford, Blackwell Publishers.

[27] Rudd, R., Baker, M, \& Hoover, T. (2000). Undergraduate agriculture student learning styles and critical thinking abilities: Is there a relationship? Journal of Agricultural Education, 41 (3), 2-12.

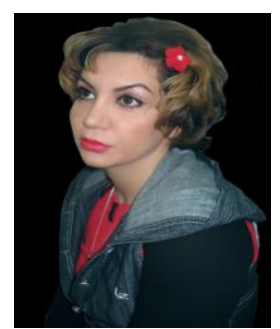

Pegah Merrikhi born on 7/11/1984 in Iran, East Azerbijan, Marand graduated from Tehran Tarbiat Moallem University (TMU) in English Translation as Bachelor then graduated from Tehran Khatam University in English Language Teaching (ELT) as M.A and now is PhD student in Turkey, Izmir, 9eylul University in English Language Teaching and Applied Linguistics. And also owns a bachelor in Tourism from Tehran Payame Noor University.

She has taught English, Russian and Turkish languages in various language institutes both in Iran and Turkey. As a multilingual person who knows five languages (Turkish, Persian, English, Russian and Arabic) she works as a local manager in a Travel agency in Turkey and as a professional tour Guide. 